\title{
CYBERBULLYING IN JAPAN: AN EXPLORATORY STUDY
}

\author{
Reinis Udris \\ Osaka University \\ Suita-shi, Yamadaoka 1-2, 565-0871, Osaka, Japan \\ udris@hus.osaka-u.ac.jp
}

\begin{abstract}
Cyberbullying is a growing problem among adolescents and adults alike. To date, research concerning cyberbullying has focused on Europe and the Anglophone countries. This study contributes to understanding of cyberbullying by adding the case of adolescents in Japan. Participants were 899 high school students who completed a selfreport questionnaire on technology use habits, cyberbullying and cybervictimization experiences. Logistic regression analyses were used to measure the relationship between cyberbullying, cybervictimization and several independent variables, including gender, age and technology use. Results showed that $22 \%$ of the participants had experienced cybervictimization, while $7.8 \%$ admitted to cyberbullying others. Most cyberbullying cases involved classmates and the victims knew the identities of their tormentors. Multiple logistic regression analyses revealed that cybervictimization is the biggest significant predictor of cyberbullying and vice versa. Having more online friends was significantly associated with cyberbullying and cybervictimization.
\end{abstract}

Keywords: Cyberbullying, Adolescents, Technology Use, Japan

\section{INTRODUCTION}

In recent years, with the advances in technology and the affordability of the Internet, cyberbullying has become more prevalent in the lives of children and adults alike. It is usually defined as harmful behavior that is intentional and repetitive, and involves the use of information and communications technologies (Vivolo-Kantor, Martell, Holland, \& Westby, 2014). However, the idea that repetition is a necessary factor in cyberbullying has come under fire as the Internet enables instant distribution of large amounts of data to 
large populations of society (Dooley, Pyżalski, \& Cross, 2009; Law, Shapka, Hymel, Olson, \& Waterhouse, 2012; Vandebosch \& Van Cleemput, 2008).

Research shows that on average $20 \%-40 \%$ of children have suffered from cyberbullying in their lives. Cybervictimization has been associated with anxiety (Campbell, Spears, Slee, Butler, \& Kift, 2012), academic problems (Beran \& Li, 2007), depression (Baker \& Tanrıkulu, 2010; J. Wang, Nansel, \& Iannotti, 2011), decreased selfesteem (Tynes, Rose, \& Williams, 2010), suicidal thoughts (Hinduja \& Patchin, 2010) and even suicide attempts (Messias, Kindrick, \& Castro, 2014). These negative outcomes have parallels throughout literature on traditional bullying, which has been associated with negative self-image (Lunde, Frisén, \& Hwang, 2007), lower academic performance (Juvonen, Wang, \& Espinoza, 2010), depression and suicidal ideation (Klomek et al., 2008) and lower self-esteem (Salmivalli, Kaukiainen, Kaistaniemi, \& Lagerspetz, 1999). Furthermore, those who experienced traditional bullying are more likely to commit crimes in later life (Olweus, 2011). While some similarities exist between traditional bullying and cyberbullying, there are three significant differences. First, although not always perfectly, the adept technology user can conceal his or her identity and remain almost completely anonymous. Second, the Internet never sleeps and its affordability makes it very difficult to avoid cyberbullying. Third, the online world is like a large stage where anyone can become a spectator. Even a single image or a video can spread very quickly, increasing the negative effect for the victim (Hinduja \& Patchin, 2009, pp. 2025).

To explain or predict cyberbullying, researchers have employed self-reports, in which "having fun" and entertainment have been cited as the most common reasons for participation in cyberbullying (Mishna, Cook, Gadalla, Daciuk, \& Solomon, 2010; Rafferty \& Vander Ven, 2014; Raskauskas \& Stoltz, 2007). Others have applied the theory of planned behavior (Heirman \& Walrave, 2012), the routine activities theory (Navarro \& Jasinski, 2012), and online disinhibition (Udris, 2014) as possible predictors of cyberbullying. Internet addiction (Chang et al., 2014), school violence and alcohol and drug use have also been associated with cyberbullying (Pelfrey \& Weber, 2013).

\section{Cyberbullying in Japan}

Research on cyberbullying in Japan is still in its infancy. Most of the small body of research has dealt only with frequencies and basic questions. A study of 2,599 elementary school children in the Kyoto area revealed that $12.5 \%$ (14.5\% for females; $11.3 \%$ for 
males) had experienced cybervictimization, while $10.6 \%$ (12.8\% for females; $8.4 \%$ for males) admitted to cyberbullying others. The difference in cyberbullying and cybervictimization frequencies between genders was statistically significant (Hara, 2011). A survey at nine junior high schools in Japan by Terado, Nagaura, and Tominaga (2010) found that of 5,357 students surveyed (51\% male, $47.4 \%$ female, $1.6 \%$ unknown) $8.66 \%$ were engaged in cyberbullying others. Interestingly, female perpetrators outnumbered males by $10.9 \%$ to $6.4 \%$ in this sample. The researchers argued that cyberbullying is less direct and physical than traditional bullying and thus more females might engage in it compared to males. The study also revealed a large overlap of traditional bullying and cyberbullying: $81.24 \%$ of cyberbullies were also traditional bullies (Terado et al., 2010). Japan's Ministry of Education conducts its own surveys and their last report showed that $4.7 \%$ of students in 2013 in the primary and secondary education system "got teased, harassed or slandered through mobile phones, computers or other technological devices" (Ministry of Education, 2014).

Barlett et al. (2013) surveyed college-aged students in Japan and the U.S. to test two opposing hypotheses. The first one was the idea that independent self-construals lead to more cyberbullying, which the researchers expected to have a greater effect on the U.S. sample due to cultural differences between the countries. The second hypothesis was that technology affordability, in which Japan is ahead of the U.S., would encourage more cyberbullying and show greater effect in Japan. However, the researchers found more cyberbullying in the U.S. sample, which favors the first hypothesis. Furthermore, they concluded that cultural context does mediate cyberbullying in both countries, but the link was much stronger in the U.S. sample (Barlett et al., 2013).

Aoyama, Utsumi, and Hasegawa (2012) conducted two studies to explore cyberbullying. The first study examined parental control, Internet use and relational aggression as possible predictors of cyberbullying. There was no time frame when asking about cyberbullying experiences, and the answers ranged from 1 (none) to 4 (frequently). Among 487 junior high school students, the study found that $33 \%$ had experienced cyberbullying, $8 \%$ of whom were bullies, $7 \%$ were victims and $18 \%$ were both bullies and victims. There were no direct effects of the control practices and parental monitoring in connection with cyberbullying, but both were indirect predictors through Internet use, which in turn was significantly associated with cyberbullying and cybervictimization (Aoyama et al., 2012). The second study looked at cultural differences between Japan and the United States. The authors argued that in the West bullying was more associated with 
physical behaviors such as punching or hitting, while ijime, the equivalent word for bullying in Japan, had a more nuanced and psychological dimension to it. Participants were 142 students from Japan and 133 from the United States. The study asked the students about cyberbullying experience only for the past six months and the coded answers were 0 - no experience; $1-1$ to 4 times; and $2-5$ or more times. Results showed that students in the United States were more involved in cyberbullying than their Japanese counterparts; American students' parents monitored their online behavior more and they were more likely to seek help from parents in case of cybervictimization. The hypothesis that cyberbullying is more indirect and thus the Japanese students would be more involved in cyberbullying was not supported. Although the sample size of the study is rather small and thus limiting the interpretation and generalization of the results, it showed that Japanese students are less involved in cyberbullying and they consult their parents less than their counterparts in the United States (Aoyama et al., 2012).

\section{Purpose of the Study}

Cyberbullying studies in Japan have been disparate and scarce, leaving many questions unanswered. Some studies explore only basic frequencies, and a few have tried to use more advanced statistical methods, like regression analyses, to predict cyberbullying aggression. The purpose of this study is to contribute to filling this knowledge gap.

1) It was hypothesized that technology use measured by the time spent online, the importance of the Internet in daily life, deviant behavior (using phone in class), larger online presence compared to real world (more online friends) and parental supervision (keeping secrets about used websites) will be significant predictors of cyberbullying.

2) Based on previous studies, it was hypothesized that being a cybervictim will significantly predict cyberbullying behavior (Bauman, 2009).

3) Lastly, this study aims to bring a clearer picture of why and how cyberbullying occurs by asking the students who are directly involved in it

\section{METHODS}

\section{Participants}

A total of 941 questionnaires were distributed in six schools in Osaka, Japan. Fortytwo were excluded from the analysis due to being incomplete ( $95.5 \%$ completion rate). 
Participants were 899 senior high school students - 383 males (42.6\%), 511 females $(56.8 \%)$ and 5 not specified $(0.6 \%)$ aged between 15 and 19 years old (M=16.30, $\mathrm{SD}=.931$ ). The sample was comprised of students in the first through third year in senior high school: $44.0 \%, 36.3 \%$ and $19.7 \%$ respectively. The six schools that agreed to participate in the survey were not randomly chosen, but they did represent different academic levels according to their national exam scores. Two of the schools could be categorized as elite, one was above average, one just around average and two were below average. The survey for this study was conducted September through November 2012.

\section{Measures}

To date, studies on cyberbullying have varied greatly in their measures and time frames, leading to disparate results (Tokunaga, 2010; Vivolo-Kantor et al., 2014). Previous studies have been conducted without any specific time frame (Hinduja \& Patchin, 2008; Juvonen \& Gross, 2008; Li, 2010), simply referring to the past couple of months (Kowalski \& Limber, 2007; Mishna et al., 2010), one year (Görzig \& Ólafsson, 2013; Jang, Song, \& Kim, 2014; Messias et al., 2014) or a combination of a certain time frames and frequencies (Brown, Demaray, \& Secord, 2014; Wensley \& Campbell, 2012). This study asked the respondents about cyberbullying activities since they started elementary school, with a follow up question inquiring about the past six months. The two time frames can then be investigated and compared separately leading to more indepth analysis of the issue. The overall time frame should be interpreted with caution as a student who was cyberbullied in the past might hold completely different normative beliefs, and his/her technology use habits can change. The items for cyberbullying and cybervictimization included various online behaviors and use of technology (e.g., upload/publish a picture or video of a friend online without permission). Multiple response questions were used to measure cyberbullying and cybervictimization experiences. Each response item for cyberbullying or cybervictimization was a dichotomous variable. These items were then collapsed into a single dichotomous variable. Thus, having at least one positive response was coded as having an overall cyberbullying or cybervictimization experience. Those respondents who were coded as 1 $=$ experience for the overall time frame had to answer an additional question asking if they have had this experience in the past six months. With this method, cyberbullying and cybervictimization experiences overall and during the past six months were coded as four separate dichotomous variables: $0=$ no experience and $1=$ experience being a cyberbully 
or a cybervictim. Furthermore, those who reported cyberbullying or cybervictimization occurrences in the overall or both (overall and past six months) time frames were asked to fill out follow-up questions. For cyberbullying, these included the possible reasons for their actions, who their targets were, and a question concerning the frequency of their actions. The first two questions allowed multiple answers. Cybervictims were asked how they felt after being targeted; who, if anyone, they told about it; who they thought had cyberbullied them; how many cyberbullies there were; how sure they were of the cyberbullies' identities; and how many times cyberbullying had happened. The first three questions allowed multiple responses.

The items concerning technology use were measured as follows. Students were asked if they use their cellular phones in class and the possible answers were coded as 1 'Don't use at school', 2 - 'Don't use during class, but use during recess', 3 - 'Use rarely', 4 - 'Use sometimes', and 5 - 'Use often'. Daily Internet use was measured in five categories: 1 - 'Less than 1 hour', 2 - '1-2 hours', 3 - '2-3 hours', 4 - '3-4 hours', and 5 - 'More than 5 hours'. Next, students were asked if they use any websites that they keep secret from their parents or guardians. The answers were coded as a dichotomous variable with 0 - 'No' and 1 - 'Yes'. The last two items, "Is Internet important to you in your daily life?" and "Do you have more online friends than the ones you meet in real life?", had Likert scale answers ranging from 1 - 'Strongly disagree', 2 - 'Disagree' to 3 - 'Agree' and 4 - 'Strongly agree'. All the regression models included gender (coded as male $=1$, female $=2$ ) and age as covariates.

\section{Procedure}

The survey questionnaires were distributed in the classroom either by the teacher in charge of the class or by the researcher. Before completing the questionnaires, students were briefed about the purpose of the study and informed of their right to not participate in the survey or to not answer any questions they would feel uncomfortable with. Time allowance for filling out the questionnaires was 15-20 minutes. Together with the questionnaires, each student also received an envelope. After the completion of the questionnaire, each student was asked to enclose his or her questionnaire in the envelope and hand it back to the researcher or the teacher in charge of the class. These procedures and the questionnaire contents were approved by the appropriate institutional ethics committee. 


\section{Data analyses}

Analyses were done using IBM SPSS Statistics 20.0. Logistic regression was chosen as the method most fit to analyze the dichotomous dependent variables expressing cyberbullying and cybervictimization experience (Menard, 2002). The significance level was set at $p<0.05$.

\section{RESULTS}

\section{Frequencies}

Of all the students in this study, 98.4\% owned at least one cellular phone. Among those, $64.1 \%$ used a smartphone. When it comes to using the Internet, $85 \%$ acknowledged going online on their phones, while $76.9 \%$ also used their PCs at home. Of all the students, $22 \%$ (17.8\% of males, $25.2 \%$ of females) admitted having been victimized, and $7.8 \%$ ( $8.1 \%$ of males, $7.6 \%$ of females) acknowledged cyberbullying others. When asked about the past six months, the number was slightly smaller $-6.7 \%$ (8.4\% of males, $5.5 \%$ of females) for cybervictimization and $2.7 \%$ (3.4\% of males, $2.2 \%$ of females) for cyberbullying.

Table 1 Prevalence of Cyberbullying by Type

\begin{tabular}{lcccc}
\hline Item & $\begin{array}{c}\text { Cyberbullying } \\
\text { (overall, \%) }\end{array}$ & $\begin{array}{c}\text { Cyberbullying } \\
(6 \text { months, \%) }\end{array}$ & $\begin{array}{c}\text { Cybervictimi } \\
\text { zation } \\
\text { (overall, \%) }\end{array}$ & $\begin{array}{c}\text { Cybervictimiz } \\
\text { ation (6 } \\
\text { months, \%) }\end{array}$ \\
\hline $\begin{array}{l}\text { Upload/publish a picture or } \\
\text { video online without } \\
\text { permission }\end{array}$ & 2.3 & 1.1 & 6.1 & 3.1 \\
\hline $\begin{array}{l}\text { Spread messages containing } \\
\text { insults or bad rumors among } \\
\text { classmates or acquaintances }\end{array}$ & 2.7 & 1.1 & 10.0 & 2.2 \\
\hline $\begin{array}{l}\text { Slander someone online } \\
\text { Send insulting or abusive } \\
\text { messages/e-mails }\end{array}$ & 3.4 & 1.3 & 7.1 & 2.0 \\
\hline $\begin{array}{l}\text { Send sexual messages/e-mails } \\
\text { Tamper with someone's profile } \\
\text { or create a fake online profile }\end{array}$ & 0.8 & 0.2 & 3.4 & 1.3 \\
\hline $\begin{array}{l}\text { Abuse or slander someone on } \\
\text { phone }\end{array}$ & 0.3 & 0.6 & 3.8 & 2.1 \\
\hline
\end{tabular}

Note: The answers were multiple response and do not add up to an exact $100 \%$. N=899. 
The most frequent response selected for cyberbullying was "Slander someone online" (3.4\%), while for cybervictimization the most commonly selected item (10\%) was "Spreading messages containing insults or bad rumors among classmates or acquaintances" (see Table 1).

Self-reported daily Internet use was measured in five categories and yielded the following results: $47.7 \%$ reported less than one hour, $17.5 \%$ reported one to two hours, $12.8 \%$ reported two to three hours, $8.5 \%$ reported three to four hours, and $13.5 \%$ reported more than four hours. A comparison between genders showed that females were heavier users than males. There were more than twice as many female users (11\%) than males $(5.1 \%)$ in the three to four hour category. Females outnumbered males in the last " $>4$ hours" category, $15.8 \%$ to $10.4 \%$.

\section{Correlations}

Cyberbullying and cybervictimization were significantly correlated with all the items except the covariates age and gender (see Table 2). All the items were tested for multicollinearity and were appropriate for regression analyses.

\section{Cyberbullying}

The most common self-reported reason for cyberbullying was "just having fun," with $45 \%$ of aggressors admitting to it (the questionnaire permitted multiple answers). This was followed by $38.6 \%$ of those who did it because they hated the victim, $14.3 \%$ who said they were bullied by the other person, $10 \%$ who joined because their friend did it, $1.4 \%$ who said they did it because their friends told them to do it and $14.3 \%$ who cited "other reasons." Finally, 15.7\% said they did not know why they did it. Respondents could choose more than one answer, which means that a single case can appear in various categories of reasons for perpetration. Students were also asked to identify their victims. Fifty-seven percent of cyberbullies admitted targeting classmates. Furthermore, 40.0\% revealed that they have cyberbullied students from other classrooms within the school, $15.7 \%$ had targeted someone from outside school, only $4.3 \%$ for someone they know online, and $14.3 \%$ for "other." As for the frequency of cyberbullying events, $25.7 \%$ of the cyberbullies said they have targeted others only once, $35.7 \%$ did it two or three times, $14.3 \%$ - four to nine times, but an alarmingly large proportion of $24.3 \%$ said they cyberbullied someone ten or more times. 
Table 2 Correlations of Gender, Age and Technology Use Items with Cyberbullying and Cybervictimization

\begin{tabular}{|c|c|c|c|c|c|c|c|c|c|c|c|}
\hline & 1 & 2 & 3 & 4 & 5 & 6 & 7 & 8 & 9 & 10 & 11 \\
\hline 1. Gender & - & -.06 & .03 & $.14 * * *$ & $.11 * *$ & $-.17^{* * * *}$ & .02 & $.09^{* * *}$ & -.06 & -.01 & -.04 \\
\hline 2. Age & & - & $.10^{* *}$ & .00 & $.07 *$ & $.11^{* *}$ & .04 & .05 & -.01 & .02 & -.01 \\
\hline 3. Phone use in class & & & - & $.23 * * *$ & $.13 * * *$ & .04 & .05 & $.14 * * *$ & $.10^{* * *}$ & $.25 * * *$ & $.20^{* * * *}$ \\
\hline 4. Internet use & & & & - & $.39 * * *$ & $.14 * * *$ & $.23 * * *$ & $.17 * * *$ & $.10^{* * *}$ & $.13 * * *$ & $.10^{* *}$ \\
\hline 5. Internet importance & & & & & - & $.16 * * *$ & $.17 * * *$ & $.15^{* * * *}$ & $.09^{* *}$ & $.14 * * *$ & $.13^{* * * *}$ \\
\hline 6. Secretive website use & & & & & & - & .16 *** & $.14 * * *$ & $.08^{*}$ & $.19 * * *$ & $.18 * * *$ \\
\hline 7. Online friends & & & & & & & - & $.21 * * *$ & $.15^{* * * *}$ & $.15 * * *$ & $.13^{* * * *}$ \\
\hline 8. Cybervictimization & & & & & & & & - & $.51^{* * * *}$ & $.33 * * *$ & $.16^{* * * *}$ \\
\hline 9. Cybervictimization (6 months) & & & & & & & & & - & $.20 * * *$ & $.22 * * *$ \\
\hline 10. Cyberbullying & & & & & & & & & & - & $.58^{* * * *}$ \\
\hline 11. Cyberbullying (6 months) & & & & & & & & & & & - \\
\hline
\end{tabular}

\section{Cybervictimization}

Most of the cyberbullying victims felt angry (38.9\%), while $24.7 \%$ were sad and $14.6 \%$ said they felt afraid. Furthermore, $21.7 \%$ couldn't classify their feelings and $6.6 \%$ had a different reaction. Finally, more than a quarter of the victims (28.3\%) said they did not care. Almost half of the victims (49\%) told their friends of what has happened, followed by $29.8 \%$ who told their parents and $6.6 \%$ talked someone else. Only $12.6 \%$ told their teachers, while almost a third (31.8\%) didn't tell anybody. Twenty-seven percent of the victims said they have been cyberbullied only once, $34.2 \%$ two or three times, $19.7 \%$ four to nine times, and $18.7 \%$ more than ten times.

Only $14.8 \%$ of the students said they didn't know who had cyberbullied them. More than half $(55.1 \%)$ of the victims claimed it was their classmates, followed by $40.3 \%$ for someone from the same school, $6.6 \%$ for someone from outside the school and $4.6 \%$ for someone they knew online and $7.7 \%$ for other. A separate question asking how sure the victims were of the perpetrator's identity shattered the ubiquitous anonymity of the cyberspace. A mere $10.8 \%$ of the victims said they had no idea and $4.6 \%$ were unsure, while $16.9 \%$ were pretty sure and $67.7 \%$ were confident about the identities or number of their tormentors. When asked how many perpetrators there were, $17.0 \%$ said they didn't know. On the other hand, $23.7 \%$ said there was one perpetrator, $34.0 \%$ reported two to three, $19.1 \%$ said four to nine and $6.2 \%$ said there were more than ten. These findings suggest that while the Internet conceals the identity of some cyberbullies, most of the time victims already know who they are. 


\section{Technology use}

Logistic regression analyses were used to examine technology use among adolescents and their experience with cyberbullying and cybervictimization (see Table 3). All four models produced statistically significant results. Most of the variables in Model 1 and Model 2 predicting cyberbullying overall and in the six-month time frame were significant. The only exceptions were the covariates and Internet use. Model 1 (-2 Log likelihood $=314.913$, Nagelkerke $R^{2}=.332$, Chi-square $\left.=8.988\right)$ explained $33 \%$ of the variation in cyberbullying.

\section{Table 3 Multiple Regression Models Predicting Cyberbullying and Cybervictimization}

\begin{tabular}{|c|c|c|c|c|c|c|c|c|}
\hline & \multicolumn{4}{|c|}{ Cyberbullying } & \multicolumn{4}{|c|}{ Cybervictimization } \\
\hline & \multicolumn{2}{|c|}{$\begin{array}{l}\text { Model } 1 \\
\text { (overall) }\end{array}$} & \multicolumn{2}{|c|}{$\begin{array}{c}\text { Model } 2 \\
(6 \text { months }) \\
\end{array}$} & \multicolumn{2}{|c|}{$\begin{array}{l}\text { Model } 3 \\
\text { (overall) }\end{array}$} & \multicolumn{2}{|c|}{$\begin{array}{c}\text { Model } 4 \\
\text { (6 months) }\end{array}$} \\
\hline & $\mathrm{b}$ & OR & $\mathrm{b}$ & OR & $\mathrm{b}$ & OR & $\mathrm{b}$ & OR \\
\hline Gender & -.36 & .70 & -.79 & .46 & .52 & $1.68 *$ & -.47 & .62 \\
\hline Age & -.18 & .83 & -.58 & $.56 \dagger$ & .13 & 1.14 & -.11 & .90 \\
\hline Phone use in class & .71 & $2.04 * * *$ & .95 & $2.58 * * *$ & .09 & 1.10 & .17 & 1.18 \\
\hline Internet use & -.05 & .95 & -.13 & .88 & .12 & $1.13 \dagger$ & .12 & 1.12 \\
\hline Internet importance & .52 & $1.68 \dagger$ & 1.66 & $5.25 * *$ & .14 & 1.15 & .60 & 1.06 \\
\hline Secretive website use & .91 & $2.48^{* * *}$ & 1.77 & $5.88 * *$ & .41 & $1.50 \dagger$ & .18 & 1.19 \\
\hline Online friends & .35 & $1.42 *$ & .62 & $1.85^{*}$ & .41 & $1.50 * *$ & .45 & $1.57 * *$ \\
\hline Cybervictimization & 1.96 & $7.13 * * *$ & & & & & & \\
\hline $\begin{array}{l}\text { Cybervictimization } \\
\text { (6 months) }\end{array}$ & & & 2.02 & $7.57 * * *$ & & & & \\
\hline Cyberbullying & & & & & 1.92 & $6.79 * * *$ & & \\
\hline Cyberbullying (6 months) & & & & & & & 1.82 & $6.18 * * *$ \\
\hline Cox and Snell $\mathrm{R}^{2}$ & .14 & & .09 & & .13 & & .05 & \\
\hline Nagelkerke $\mathrm{R}^{2}$ & .33 & & .41 & & .19 & & .12 & \\
\hline
\end{tabular}

By far the strongest predictor was cybervictimization. Those students who had been cyberbullied were more than seven times more likely to cyberbully others ( $\mathrm{OR}=7.13, \mathrm{CI}$ $=3.83-13.26, p<.001)$. The second strongest predictor was secretive website use $(\mathrm{OR}=$ $2.48, \mathrm{CI}=1.33-4.65, p<.01)$. The other significant predictors in Model 1 included phone use in class $(\mathrm{OR}=2.04, \mathrm{CI}=1.59-2.62, p<.001)$ and the number of online friends $(\mathrm{OR}=1.42, \mathrm{CI}=1.01-1.98, p=.041)$. The importance of the Internet was just outside the established $95 \%$ confidence interval for significance $(\mathrm{OR}=1.68, \mathrm{CI}=.97-$ $2.90, p=.064)$. Model $2\left(-2 \log\right.$ likelihood $=119.782$, Nagelkerke $\mathrm{R}^{2}=.411$, Chi-square 
$=3.972$ ) explained $41 \%$ of the variation in cyberbullying. Here, cybervictimization was also the most important predictor $(\mathrm{OR}=7.57, \mathrm{CI}=2.45-23.43, p<.001)$. All of the items measuring technology habits with the exception of Internet use were significant in the model. Those students who thought the Internet was an important part of their lives (OR $=5.25, \mathrm{CI}=1.50-18.32, p=.009)$ and those who used certain websites in secret from their parents or guardians $(\mathrm{OR}=5.88, \mathrm{CI}=1.99-17.39, p=.001)$ were more than five times more likely to cyberbully others. The remaining significant predictors in Model 2 were phone use in class $(\mathrm{OR}=2.58, \mathrm{CI}=1.67-3.97, p<.001)$ and the number of online friends $(\mathrm{OR}=1.85, \mathrm{CI}=1.05-3.25, p=.033)$. Model 3 ( $-2 \mathrm{Log}$ likelihood $=727.115$, Nagelkerke $R^{2}=.192$, Chi-square $\left.=11.860\right)$ and Model $4(-2$ Log likelihood $=351.328$, Nagelkerke $\mathrm{R}^{2}=.119$, Chi-square $\left.=2.876\right)$ were used to examine cybervictimization as the dependent variable. In both models, cyberbullying experience $(\mathrm{OR}=6.79, \mathrm{CI}=3.67-$ $12.55, p<.001$ and $\mathrm{OR}=6.18, \mathrm{CI}=2.15-17.77, p<.001$ ) was the most prominent predictor. The only other item significant in both models was the number of online friends $(\mathrm{OR}=1.50, \mathrm{CI}=1.17-1.92, p=.001$ and $\mathrm{OR}=1.57, \mathrm{CI}=1.12-2.18, p=.009)$. In Model 3, gender was significant, indicating that females are 1.6 times more likely to experience cybervictimization $(\mathrm{OR}=1.68, \mathrm{CI}=1.13-2.51, p=.01)$.

\section{DISCUSSION}

Based on this study and existing research, cybervictimization rates in Japan averaged 5-33\%, which is substantially lower than those reported around the world. A review of studies dealing with cyberbullying by Tokunaga (2010) showed that cybervictimization rates were $20 \%-40 \%$ on average. However, most of the reviewed studies employed European or North American samples, and none included Japanese samples. This discrepancy could be attributed to the differences in definitions and measurement of cyberbullying, as well as the time frames used. Additionally, the results can be influenced by social desirability and recall/reporter bias of the students. Furthermore, previous research has shown only a modest or even a poor correlation between self-reported bullying behavior and peer nominations (Cornell \& Brockenbrough, 2004; Lee \& Cornell, 2009). However, Aoyama et al. (2012) argue that the collectivist culture that prizes conformity discourages students from sharing their problems and seeking help, which in turn can increase social desirability for the Japanese respondents. 
The most frequently cited cyberbullying item in this study was "Spreading messages containing insults or bad rumors among classmates or acquaintances," which was reported by $10 \%$ of the students. A study of youths in the United States by Mitchell, Finkelhor, Jones, and Wolak (2012) showed that $7.1 \%$ had received sexual images and $5.7 \%$ said they received explicitly nude images. In this study, the number stood slightly low at $3.8 \%$, but research has shown that these messages can have a negative impact on the students as well as those around them (Comartin, Kernsmith, \& Kernsmith, 2013).

Self-reported answers from the cyberbullies in this study showed that close to half of them $(45 \%)$ did it "just to have fun," corroborating previously conducted studies in the United States and Canada (Mishna et al., 2010; Rafferty \& Vander Ven, 2014; Raskauskas $\&$ Stoltz, 2007). This indicates that children don't see their actions as anything more serious than a game, although in some cases the consequences can be very dire. As for the relationships with the victims, $40 \%$ of cyberbullies admitted targeting their classmates. No other study in Japan dealing with cyberbullying has examined this, but research on traditional bullying shows that most cases involve classmates (Akiba, 2004; Shariff, 2008, p. 51). In this study, just over a quarter of cyberbullies reported bullying others only once, while $24.3 \%$ admitted to doing it more than ten times. The argument about repetitiveness as a necessary factor to define an action as cyberbullying has not yet been settled. It has been considered as a prerequisite factor in traditional bullying (Olweus, 2010). However, some scholars argue that repetitiveness is not needed when it comes to cyberbullying as uploading only one image online can start a chain of actions when Internet users share it (Hinduja \& Patchin, 2009, p. 18; Peter K. Smith, 2012). Thus, only one action can lead to a near infinite circulation of harmful messages or pictures.

Previous research reveals the negative effects and emotional outcomes cyberbullying can have on an individual. This study directly inquired about the emotions felt by the students who were cyberbullied, many of whom (38.9\%) said they felt "angry." At the same time, $28.3 \%$ reported that they didn't care, showing that they could ignore or shrug off the taunts directed at them. The question is does a situation where the "victim" apparently doesn't suffer any emotional abuse count as cyberbullying? Inquiring about cyberbullying without a clear definition or follow up questions can lead to disparity in cybervictimization rates.

While almost half of the victims consulted with their friends (49\%), almost a third (31.8\%) said they didn't tell anybody of what happened. Slonje and Smith (2008) reported that exactly half of the Swedish students they studied didn't consult with anyone. 
Only $12.6 \%$ of the students in this study consulted teachers, which may indicate a lack of trust between children and their teachers.

Contrary to the belief that cyberbullying is shrouded in complete anonymity, more than half $(55.1 \%)$ reported that the perpetrator was a classmate, while only $14.8 \%$ said that they had no idea who had done it. A number of factors could influence the anonymity of the action itself, but this result does show that in many cases, traditional and cyberbullying cases overlap, which in turn would make it quite easy for the victim to figure out who did it. A number of studies have reported most of the cybervictims also experience traditional bullying (e.g., Olweus, 2012; Raskauskas, 2009; Ybarra, DienerWest, \& Leaf, 2007). Furthermore, 67.7\% of the cybervictims answered that they are confident of the bullies' identity, corroborating findings by Juvonen and Gross (2008) in the United Sates. A question pertaining to the number of perpetrators revealed that $17 \%$ of the students had no idea, while $23.7 \%$ claimed there was only one. That leaves $59.7 \%$ of cases where there was a group of aggressors (of which 6.2\% included at least ten). Previous studies have shown that the majority of traditional bullying cases in Japan involved a group of perpetrators (Akiba, 2004; Smorti, Menesini, \& Smith, 2003), and this study reveals that the same pattern applies to cyberbullying as well.

The multivariate regression analyses showed that most of the technology use items predicting cyberbullying were significant predictors, explaining 33\% (Model 1) and 41\% (Model 2) of the variation in the overall time period and for the past six months. The strongest predictor of cyberbullying was cybervictimization, with victims being more than seven times more likely to engage in cyberbullying. This shows that bullying is closely related victimization. Research on traditional bullying in Japan has shown that $53.7 \%$ and up to $27.4 \%$ of aggressors in elementary and high school level had been victimized within the past 12 months prior to the survey (Morita, Soeda, Soeda, \& Taki, 1999). Furthermore, cyberbullying experience was the most significant predictor in Models 3 and 4 where cybervictimization was the dependent variable. Students with cyberbullying experience were up to six times more likely to experience victimization. These findings are in line with Bauman (2009) who employed a rural sample in United States, but they have to be interpreted with caution as it is impossible to tell which action has occurred first in a cross-sectional study. A longitudinal study is needed to investigate these findings further to see how being a victim can turn one into a bully and vice-versa. 
In Model 1 and Model 2, students who reported using websites in secret from their parents were up to 5.9 times more likely to cyberbully others. The websites visited may indicate risky online behavior, which could lead to more victimization, but the item was not significant in either of the regression models with cybervictimization as the dependent variable. Lower parental control or a propensity for deviant behavior in general could explain this disparity. This view is supported by Kowalski, Giumetti, Schroeder, and Lattanner (2014) who reviewed a large number of studies and found that lack of parental monitoring of children's online activities and weaker social bonds between the parents and children were more common among the perpetrators of Internet harassment. Jing Wang, Iannotti, and Nansel (2009) also reported parental support being negatively associated with cyberbullying among adolescents in United States.

Internet importance was just outside the established significance level in Model 1 ( $p$ $=.064)$, but in Model 2 those students who scored higher on this item were more than five times $(p=.009)$ more likely to cyberbully others. Questions measuring attitudes and normative beliefs were measured in the present time, while the cyberbullying experience could be in the past when those beliefs were different. Thus, the shorter time frame yields more reliable results and is less biased. Increased importance of the Internet and the inability to function daily without it could be linked to addiction, which has already been associated with cyberbullying and cybervictimization, among other issues (Chang et al., 2014). Future research is needed to determine how one's attitude towards the Internet in general shapes usage habits and why would it lead to cyberbullying.

The next item measured phone use in class. Those students who reported doing so more often were up to 2.5 times more like to cyberbully others. Using one's cellular phone in class usually implies a clear breach of the established rules of the school (none of the schools in this study permitted phone use during class). Breaking rules in real life can easily be extended to online where there is more anonymity and a smaller chance of repercussions. This corroborates the findings of Ybarra and Mitchell (2007), who found that in the United States rule breaking was a significant predictor of Internet harassment perpetration.

Lastly, having more online friends compared to real life was the only item significant in all four regression models. Those students who had more online friends were up to 1.8 times more likely to cyberbully others, while at the same time they were up to 1.5 times more likely to be victimized. Concurrently, Internet use, which was strictly measured as the time on average each student spends online, was not significant 
in any of the regression models. Thus, it is the quality of the time and the social interactions or relationships one has online that are more important when it comes to cyberbullying and cybervictimization. The link between Internet use and cyberbullying is not settled. Some studies find it significant (Juvonen \& Gross, 2008), while others do not (P. K. Smith et al., 2008).

The results presented in this study give researchers and educators a glimpse of what factors contribute to cyberbullying and what exactly goes on in the minds of adolescents who have experienced cyberbullying, either as perpetrators or victims. It is clear that most cases involve classmates or others from the same school. Victims know the identities of their tormentors personally, and the cyberbullying occurs within a group. It could mean that while traditional bullying and cyberbullying overlap most of the time, cyberbullying in Japan is perhaps more closely related to traditional bullying, because Japanese society values conformity and elevates groups over individuals. Future research should examine these subtle combinations of factors and determine how much local culture mediates patterns of cyberbullying, i.e., the number of perpetrators, victim's knowledge of perpetrators and the overlap between traditional and cyberbullying.

\section{LIMITATIONS}

Some limitations of the current study must be taken into account. First, this study is cross-sectional and the results should be interpreted as such. Second, the sample is not random as only the schools that agreed to participate were included. Third, this study had a particular focus on Japan; therefore, future research should determine if these results can be generalized to other countries and age populations. Fourth, this study employed self-report questionnaires, which can lead to socially desirable responses and reporting bias.

\section{CONCLUSIONS}

Research to date has mostly focused on the United States, Europe and a few other select countries. This study extends our knowledge on cyberbullying by examining high school students in Japan. It shows how certain technology use habits are significantly associated with cyberbullying and points to possible cultural characteristics that might mediate this connection. Furthermore, it reveals that it is the quality or the way we interact online and not the time spent online that is significant when it comes to cyberbullying and cybervictimization. Interestingly, this study shows that considering the 
Internet an indispensable necessity in daily life is associated with higher cyberbullying perpetration. Misuse of technology or the simple act of breaking school rules and using a phone in class had a clear association with cyberbullying.

Finally, the findings of the current study have important implications for policy change and future research. First, while the Internet does offer a certain level of anonymity, this study shows that most cybervictims knew their bullies. Results also indicate that cyberbullying happens mostly between classmates, which explains how victims might know their tormentors. Bullying and cyberbullying are closely related, and so prevention programs should include both dimensions - the offline and the online. Second, parents as well as teachers should be encouraged to discuss the possible pros and cons of the Internet to build trust so fewer children engage in risky online behavior and consequent cyberbullying. Increased trust would help children confide in adults when problems arise. Third, our social lives have become more and more intertwined with cyberspace, blurring the boundary of reality (Hand, 2010). Students who have a very active social life in cyberspace should be encouraged to follow the same rules that apply in the real world. Just because you sometimes do not see the face of your online friend or do not shake their hands does not mean freedom from the basic norms of courtesy.

\section{REFERENCES}

Akiba, M. (2004). Nature and correlates of Ijime - Bullying in Japanese middle school. International Journal of Educational Research, 41(3), 216-236. http://dx.doi.org/10.1016/j.jier.2005.07.002.

Aoyama, I., Utsumi, S., \& Hasegawa, M. (2012). Cyberbullying in Japan. In Q. Li, D. Cross and P.K. Smith (Eds.), Cyberbullying in the global playground: Research from international perspectives (pp. 183-201). Oxford, England: John Wiley \& Sons.

Baker, Ö.E., \& Tanrıkulu, İ. (2010). Psychological consequences of cyber bullying experiences among Turkish secondary school children. Procedia - Social and Behavioral Sciences, 2(2), 2771-2776. http://dx.doi.org/10.1016/j.sbspro.2010.03.413.

Barlett, C.P., Gentile, D.A., Anderson, C.A., Suzuki, K., Sakamoto, A., Yamaoka, A., \& Katsura, R. (2013). Cross-cultural differences in cyberbullying behavior: A shortterm longitudinal study. Journal of Cross-Cultural Psychology, 45(2), 300-313. http://dx.doi.org/10.1177/0022022113504622. 
Bauman, S. (2009). Cyberbullying in a rural intermediate school: An exploratory study. Journal of Early Adolescence, 30(6), 803-833. http://dx.doi.org/10.1177/0272431609350927.

Beran, T., \& Li, Q. (2007). The relationship between cyberbullying and school bullying. Journal of Student Wellbeing, 1(2), 15-33.

Brown, C.F., Demaray, M.K., \& Secord, S.M. (2014). Cyber victimization in middle school and relations to social emotional outcomes. Computers in Human Behavior, 35, 12-21. http://dx.doi.org/10.1016/j.chb.2014.02.014.

Campbell, M., Spears, B., Slee, P., Butler, D., \& Kift, S. (2012). Victims' perceptions of traditional and cyberbullying, and the psychosocial correlates of their victimisation. Emotional and Behavioural Difficulties, 17(3-4), 389-401. http://dx.doi.org/10.1080/13632752.2012.704316.

Chang, F.C., Chiu, C.H., Miao, N.F., Chen, P.H., Lee, C.M., Chiang, J.T., \& Pan, Y.C. (2014). The relationship between parental mediation and Internet addiction among adolescents, and the association with cyberbullying and depression. Comprehensive psychiatry, 57, 21-28. http://dx.doi.org/10.1016/j.comppsych.2014.11.013.

Comartin, E., Kernsmith, R., \& Kernsmith, P. (2013). "Sexting" and sex offender registration: Do age, gender, and sexual orientation matter? Deviant Behavior, 34(1), 38-52. http://dx.doi.org/10.1080/01639625.2012.707534.

Cornell, D.G., \& Brockenbrough, K. (2004). Identification of bullies and victims. Journal of School Violence, 3(2-3), 63-87. http://dx.doi.org/10.1300/J202v03n02_05.

Dooley, J.J., Pyżalski, J., \& Cross, D. (2009). Cyberbullying versus Face-to-Face bullying. Zeitschrift für Psychologie / Journal of Psychology, 217(4), 182-188. http://dx.doi.org/10.1027/0044-3409.217.4.182.

Görzig, A., \& Ólafsson, K. (2013). What makes a bully a cyberbully? unravelling the characteristics of cyberbullies across twenty-five european countries. Journal of Children and Media, 7(1), 9-27. http://dx.doi.org/10.1080/17482798.2012.739756.

Hand, M. (2010). The rise and fall of cyberspace, or how cyberspace turned inside out. In J.R. Hall, L. Grindstaff \& M.C. Lo (Eds.), Handbook of Cultural Sociology (pp. 357-367). New York: Routledge.

Hara, K. (2011). The realities of cyber bullying and factor analysis (i): The mobility of scholastic achievement. Bulletin of the Faculty of Education, 22, 133-152.

Heirman, W., \& Walrave, M. (2012). Predicting adolescent perpetration in cyberbullying: An application of the theory of planned behavior. Psicothema, 24(4), 614-620. 
Hinduja, S., \& Patchin, J.W. (2008). Cyberbullying: An exploratory analysis of factors related to offending and victimization. Deviant Behavior, 29(2), 129-156. http://dx.doi.org/10.1080/01639620701457816.

Hinduja, S., \& Patchin, J.W. (2009). Bullying beyond the schoolyard: Preventing and responding to cyberbullying. Thousand Oaks, CA: Sage.

Hinduja, S., \& Patchin, J.W. (2010). Bullying, cyberbullying, and suicide. Archives of Suicide Research, 14(3), 206-221. http://dx.doi.org/10.1080/13811118.2010.494133.

Jang, H., Song, J., \& Kim, R. (2014). Does the offline bully-victimization influence cyberbullying behavior among youths? Application of General Strain Theory. Computers in Human Behavior, 31, 85-93. http://dx.doi.org/10.1016/j.chb.2013.10.007.

Juvonen, J., \& Gross, E.F. (2008). Extending the school grounds?--Bullying experiences in cyberspace. Journal of School health, 78(9), 496-505. http://dx.doi.org/10.1111/j.1746-1561.2008.00335.x.

Juvonen, J., Wang, Y., \& Espinoza, G. (2010). Bullying experiences and compromised academic performance across middle school grades. The Journal of Early Adolescence, 31(1), 152-173. http://dx.doi.org/10.1177/0272431610379415.

Klomek, A.B., Sourander, A., Kumpulainen, K., Piha, J., Tamminen, T., Moilanen, I., Gould, M.S. (2008). Childhood bullying as a risk for later depression and suicidal ideation among Finnish males. Journal of affective disorders, 109(1), 47-55. http://dx.doi.org/10.1016/j.jad.2007.12.226.

Kowalski, R.M., Giumetti, G.W., Schroeder, A.N., \& Lattanner, M.R. (2014). Bullying in the digital age: a critical review and meta-analysis of cyberbullying research among youth. Psychological Bulletin, 140(4), 1073-1137. http://dx.doi.org/10.1037/a0035618.

Kowalski, R.M., \& Limber, S.P. (2007). Electronic bullying among middle school students. Journal of Adolescent Health, 41(6), S22-S30. http://dx.doi.org/10.1016/j.jadohealth.2007.08.017.

Law, D.M., Shapka, J.D., Hymel, S., Olson, B.F., \& Waterhouse, T. (2012). The changing face of bullying: An empirical comparison between traditional and internet bullying and victimization. Computers in Human Behavior, 28(1), 226-232. http://dx.doi.org/10.1016/j.chb.2011.09.004.

Lee, T., \& Cornell, D. (2009). Concurrent validity of the olweus bully/victim questionnaire. Journal of School Violence, 9(1), 56-73. 
http://dx.doi.org/10.1080/15388220903185613.

Li, Q. (2010). Cyberbullying in high schools: A study of students' behaviors and beliefs about this new phenomenon. Journal of Aggression, Maltreatment \& Trauma, 19(4), 372-392._http://dx.doi.org/10.1080/10926771003788979.

Lunde, C., Frisén, A., \& Hwang, C.P. (2007). Ten-year-old girls' and boys' body composition and peer victimization experiences: Prospective associations with body $\begin{array}{llll}\text { satisfaction. } & \text { Body } & \text { Image, } & 4(1),\end{array}$ http://dx.doi.org/10.1016/j.bodyim.2006.10.002.

Menard, S. (2002). Applied logistic regression analysis (2 ed.). Thousand Oaks, CA: Sage.

Messias, E., Kindrick, K., \& Castro, J. (2014). School bullying, cyberbullying, or both: correlates of teen suicidality in the 2011 CDC Youth Risk Behavior Survey. Comprehensive psychiatry, 55(5), 1063-1068. http://dx.doi.org/10.1016/j.comppsych.2014.02.005.

Ministry of Education, Culture, Sports, Sciences \& Technology. (2014). Jidou seito no mondai koudou nado seito shidou ue no shomondai ni kansuru chousa. Retrieved October 18, 2013, from http://www.mext.go.jp/b_menu/houdou/26/10/_icsFiles/afieldfile/2014/10/16/1351 936_01_1.pdf.

Mishna, F., Cook, C., Gadalla, T., Daciuk, J., \& Solomon, S. (2010). Cyber bullying behaviors among middle and high school students. The American Journal of Orthopsychiatry, $\quad 80(3), \quad 362-374 . \quad$ http://dx.doi.org/10.1111/j.19390025.2010.01040.x.

Mitchell, K.J., Finkelhor, D., Jones, L.M., \& Wolak, J. (2012). Prevalence and characteristics of youth sexting: A national study. Pediatrics, 129(1), 13-20. http://dx.doi.org/10.1542/peds.2011-1730.

Morita, Y., Soeda, H., Soeda, K., \& Taki, M. (1999). Japan. In R. Catalano, J. Junger-Tas, Y. Morita, D. Olweus, and P. Slee (Eds.), The Nature of School Bullying (pp.309323). London and New York: Routledge.

Navarro, J.N., \& Jasinski, J.L. (2012). Going cyber: Using routine activities theory to predict cyberbullying experiences. Sociological Spectrum, 32(1), 81-94. http://dx.doi.org/10.1080/02732173.2012.628560.

Olweus, D. (2010). Understanding and researching bullying: Some critical issues. In S.R. Jimerson, S. Swearer and D.L. Espelage (Eds.), Handbook of bullying in schools: An 
international perspective (pp.9-33). New York: Routledge.

Olweus, D. (2011). Bullying at school and later criminality: findings from three Swedish community samples of males. Criminal Behaviour and Mental Health, 21(2), 151156. http://dx.doi.org/10.1002/cbm.806.

Olweus, D. (2012). Cyberbullying: An overrated phenomenon? European Journal of $\begin{array}{lll}\text { Developmental Psychology, 520-538. } & \text { 9(5), }\end{array}$ http://dx.doi.org/10.1080/17405629.2012.682358.

Pelfrey, W.V., \& Weber, N.L. (2013). Keyboard gangsters: Analysis of incidence and correlates of cyberbullying in a large urban student population. Deviant Behavior, 34(1), 68-84. http://dx.doi.org/10.1080/01639625.2012.707541.

Rafferty, R., \& Vander Ven, T. (2014). "I Hate Everything about You”: A qualitative examination of cyberbullying and on-line aggression in a college sample. Deviant Behavior, 35(5), 364-377. http://dx.doi.org/10.1080/01639625.2013.849171.

Raskauskas, J. (2009). Text-Bullying: Associations with traditional bullying and depression among New Zealand adolescents. Journal of School Violence, 9(1), 74-97. http://dx.doi.org/10.1080/15388220903185605.

Raskauskas, J., \& Stoltz, A.D. (2007). Involvement in traditional and electronic bullying among adolescents. Developmental psychology, 43(3), 564-575. http://dx.doi.org/10.1037/0012-1649.43.3.564.

Salmivalli, C., Kaukiainen, A., Kaistaniemi, L., \& Lagerspetz, K.M.J. (1999). SelfEvaluated self-esteem, peer-evaluated self-esteem, and defensive egotism as predictors of adolescents' participation in bullying situations. Personality and Social Psychology Bulletin, 25(10), 1268-1278. http://dx.doi.org/10.1177/0146167299258008.

Shariff, S. (2008). Cyber-bullying: Issues and solutions for the school, the classroom and the home. London: Routledge.

Slonje, R., \& Smith, P.K. (2008). Cyberbullying: Another main type of bullying? $\begin{array}{llll}\text { Scandinavian journal of psychology, } & 49(2), & 147-154 .\end{array}$ http://dx.doi.org/10.1111/j.1467-9450.2007.00611.x.

Smith, P.K. (2012). Cyberbullying: Challenges and opportunities for a research program A response to Olweus. European Journal of Developmental Psychology, 9(5), 553558. http://dx.doi.org/10.1080/17405629.2012.689821.

Smith, P.K., Mahdavi, J., Carvalho, M., Fisher, S., Russell, S., \& Tippett, N. (2008). Cyberbullying: its nature and impact in secondary school pupils. Journal of child 
psychology and psychiatry, 49(4), 376-385. http://dx.doi.org/10.1111/j.14697610.2007.01846.x.

Smorti, A., Menesini, E., \& Smith, P.K. (2003). Parents' definitions of children's bullying in a five-country comparison. Journal of Cross-Cultural Psychology, 34(4), 417-432. http://dx.doi.org/10.1177/0022022103034004003.

Terado, T., Nagaura, H., \& Tominaga, Y. (2010). A factual investigation about use of information device and experiences cyberbullying in junior high-school students. The Journal of Human Development and Clinical Psychology, 16, 89-106.

Tokunaga, R.S. (2010). Following you home from school: A critical review and synthesis of research on cyberbullying victimization. Computers in Human Behavior, 26(3), 277-287. http://dx.doi.org/10.1016/j.chb.2009.11.014.

Tynes, B.M., Rose, C.A., \& Williams, D.R. (2010). The development and validation of the online victimization scale for adolescents. Cyberpsychology: Journal of Psychosocial Research on Cyberspace, 4(2), article 1.

Udris, R. (2014). Cyberbullying among high school students in Japan: Development and validation of the Online Disinhibition Scale. Computers in Human Behavior, 41, 253-261. http://dx.doi.org/10.1016/j.chb.2014.09.036.

Vandebosch, H., \& Van Cleemput, K. (2008). Defining cyberbullying: a qualitative research into the perceptions of youngsters. Cyberpsychology and Behavior, 11(4), 499-503. http://dx.doi.org/10.1089/cpb.2007.0042.

Vivolo-Kantor, A.M., Martell, B.N., Holland, K.M., \& Westby, R. (2014). A systematic review and content analysis of bullying and cyber-bullying measurement strategies. Aggression and Violent Behavior, 19(4), 423-434. http://dx.doi.org/10.1016/j.avb.2014.06.008.

Wang, J., Iannotti, R.J., \& Nansel, T.R. (2009). School bullying among adolescents in the United States: Physical, verbal, relational, and cyber. Journal of Adolescent Health, 45(4), 368-375. http://dx.doi.org/10.1016/j.jadohealth.2009.03.021.

Wang, J., Nansel, T.R., \& Iannotti, R.J. (2011). Cyber and traditional bullying: differential association with depression. Journal of Adolescent Health, 48(4), 415417. http://dx.doi.org/10.1016/j.jadohealth.2010.07.012.

Wensley, K., \& Campbell, M. (2012). Heterosexual and nonheterosexual young university students' involvement in traditional and cyber forms of bullying. Cyberpsychology, Behavior, and Social Networking, 15(12), 649-654. http://dx.doi.org/10.1089/cyber.2012.0132. 
Ybarra, M.L., Diener-West, M., \& Leaf, P.J. (2007). Examining the overlap in internet harassment and school bullying: implications for school intervention. Journal of Adolescent Health, $41(6)$, S42-S50. http://dx.doi.org/10.1016/j.jadohealth.2007.09.004.

Ybarra, M.L., \& Mitchell, K.J. (2007). Prevalence and frequency of Internet harassment instigation: Implications for adolescent health. Journal of Adolescent Health, 41(2), 189-195. http://dx.doi.org/10.1016/j.jadohealth.2007.03.005. 